\title{
Antibacterial Properties of D-Amino Acid Oxidase: Impact on the Food Industry
}

\author{
Giorgia Letizia Marcone ${ }^{1 *}$, Elisa Binda ${ }^{1}$, Elena Rosini ${ }^{1}$, Monica Abbondi ${ }^{2,3}$ and \\ Loredano Pollegioni, ${ }^{1,3}$
}

${ }^{1}$ Department of Biotechnology and Life Sciences, University of Insubria, Varese, Italy, ${ }^{2} D$-Amino Acids International Reference Center, Gerenzano, Italy, ${ }^{3}$ Fondazione Istituto Insubrico Ricerca per la Vita, Gerenzano, Italy

OPEN ACCESS

Edited by: Javier Carballo, University of Vigo, Spain

Reviewed by:

Vladimir I. Tishkov, Lomonosov Moscow State University, Russia Santi M. Mandal, Indian Institute of Technology Kharagpur, India

*Correspondence:

Giorgia Letizia Marcone giorgia.marcone@uninsubria.it

Specialty section: This article was submitted to

Food Microbiology,

a section of the journal

Frontiers in Microbiology

Received: 30 July 2019 Accepted: 15 November 2019 Published: 03 December 2019

Citation:

Marcone GL, Binda E, Rosini E, Abbondi $M$ and Pollegioni L (2019)

Antibacterial Properties of

D-Amino Acid Oxidase: Impact on the Food Industry.

Front. Microbiol. 10:2786. doi: 10.3389/fmicb.2019.02786
Food quality is also related to safety and prevention of spoilage. Biological antimicrobial agents represent suitable alternatives to clinical preservatives in food industry to increase both safety and stability of aliments. Here, we focused on the enzyme D-amino acid oxidase (DAAO) from the yeast Rhodotorula gracilis, a well-studied protein for biotechnological use based on its stability, high activity, and easy recombinant production. DAAO catalyzes the $\mathrm{O}_{2}$-dependent oxidative deamination of $\mathrm{D}$-enantiomer of amino acids generating $\alpha$-keto acids, ammonia, and hydrogen peroxide. DAAO shows antibacterial activity on both Gram-positive and Gram-negative bacteria in the presence of D-alanine when tested on plates and reduced by half their growth when tested on liquid cultures. Control experiments performed with alternative amino acid-specific flavoenzymes (able or not to generate $\mathrm{H}_{2} \mathrm{O}_{2}$ acting on amino acids), a DAAO inactive variant, catalase $\left(\mathrm{H}_{2} \mathrm{O}_{2}\right.$ scavenger), and L-amino acids instead of D-alanine identified $\mathrm{H}_{2} \mathrm{O}_{2}$ as the antibacterial agent. DAAO showed a good ability to decrease the bacterial growth on various food stuffs: e.g., 10-fold less colonies were formed on grated cheese incubated for $16 \mathrm{~h}$ at $37^{\circ} \mathrm{C}$ when a tiny amount (0.01 mg corresponding to 1.2 units) of DAAO was added. No exogenous D-amino acids were added since DAAO used the ones naturally occurring or the ones generated during ripening. Notably, simultaneously to $\mathrm{H}_{2} \mathrm{O}_{2}$ generation, DAAO also acts as $\mathrm{O}_{2}$-scavenger thus further hampering food deterioration.

Keywords: antibacterials, D-amino acids, D-amino acid oxidase, flavoenzymes, food safety, food preservation

\section{INTRODUCTION}

The presence of bacterial pathogens in food may be responsible for spoilage and foodborne disease incidence. Furthermore, an increase of morbidity and mortality has been related to the emergence of multidrug resistant and disinfectant resistant bacteria (Vijayakumar and Sandle, 2019). Actually, preservative agents are added to ensure food safety and prevent spoilage. In this, both chemical and biological preservatives are used, for a review, see Brul and Coote (1999). Safety and stability of manufactured foods is gained by adding chemical preservatives such as weak acids, i.e., benzoic and sorbic acids (Brul and Coote, 1999): their use can cause microbiological resistance. Moreover, pathogenic bacteria, like Listeria monocytogenes cannot be fully eliminated in food products by chemical preservatives, which also do not delay the 
growth of spoilage microorganisms (Tajkarimi et al., 2010). On this side, the antibacterial effects of hydrogen peroxide have been extensively investigated due to its possible involvement in a number of important biological events in which bacterial cells are either killed or their growth inhibited. Hydrogen peroxide generates a short lined singlet $\mathrm{O}_{2}$ species, which is extremely biocidal, as well as superoxide radicals that in the presence of trace amounts of transition metal ions generate biocidal hydroxyl radicals. Hydrogen peroxide has a potential to be used in a variety of ways in the food industry as antimicrobial agent in water and dairy products (Juven and Pierson, 1996).

In recent years, interest focused on the use of natural antimicrobial agents in foods, such as antimicrobial peptides and occurring proteins, e.g., lysozyme, lactoperoxidase, or lactoferrin. In the food industry, aerobic microorganisms are affected by glucose oxidase-catalase system, which acts by depleting available oxygen and generating hydrogen peroxide (Wong et al., 2008).

D-Amino acid oxidase (EC 1.4.3.3, DAAO) is a dimeric enzyme containing one molecule of FAD per $40 \mathrm{kDa}$ monomer. It belongs to the dehydrogenase/oxidase class of flavoproteins that catalyze with a strict stereospecificity, the oxidative deamination of $\mathrm{D}$-amino acids to give $\alpha$-keto acids and ammonia: reoxidation of reduced flavin by $\mathrm{O}_{2}$ generates hydrogen peroxide (Pollegioni et al., 2007). Microbial DAAOs (especially the ones from the yeast Rhodotorula gracilis and Trigonopsis variabilis) possess properties compatible with industrial applications: e.g., high activity on a number of neutral and polar D-amino acids, a strong interaction with the cofactor and a good stability (Pilone et al., 1989; Pollegioni et al., 1993, 2008; Molla et al., 2000; Pilone and Pollegioni, 2002). Accordingly, yeast DAAO is used in the production of 7-amino cephalosporanic acid from cephalosporin $\mathrm{C}$, in the resolution of natural and synthetic racemic mixtures of amino acids and for the detection and quantification of D-amino acids in biological samples and foodstuff (a good parameter of bacterial contamination or aging) (Pollegioni and Molla, 2011).

Here, we report on the antibacterial activity of DAAO from Rhodotorula gracilis: its reaction uses $\mathrm{O}_{2}$ and generates hydrogen peroxide, a trait used in food preservation.

\section{MATERIALS AND METHODS}

\section{Materials}

All chemical reagents, including media, antibiotics, and catalase, were purchased from Sigma-Aldrich, Milan, Italy. All the chemical reagents were used without additional purification.

\section{Bacterial Strains and Growth Conditions}

Escherichia coli ATCC 35218, Bacillus subtilis ATCC 6633, Pseudomonas aeruginosa ATCC 10145, Salmonella enterica subsp. typhimurium ATCC 6994, and Staphylococcus aureus ATCC 6538P (methicillin susceptible S. aureus, MSSA) were obtained from the American Type Culture Collection (ATCC). Acinetobacter baumannii, Enterococcus faecalis, and Yersinia enterocolitica were clinical isolates. E. coli, B. subtilis, P. aeruginosa, S. enterica subsp. typhimurium, E. faecalis, Y. enterocolitica, and A. baumannii were propagated overnight in Luria Bertani medium (LB, 2\% tryptone, $2 \%$ yeast extract, and $1 \% \mathrm{NaCl}$ ). S. aureus in Mueller Hinton broth 2 (MHB2, $0.3 \%$ beef infusion solids, $1.75 \%$ casein hydrolysate, and $0.15 \%$ starch) with continuous shaking at $200 \mathrm{rpm}$ and $37^{\circ} \mathrm{C}$. For exponential growth, overnight cultures were transferred to fresh medium: start cultures showed an optical density at $600 \mathrm{~nm}\left(\mathrm{OD}_{600 \mathrm{~nm}}\right)$ of 0.1 . Storage at $-20^{\circ} \mathrm{C}$ in $20 \%$ glycerol was used for long-term preservation.

\section{Enzymes}

Recombinant Rhodotorula gracilis DAAO wild-type was produced in E. coli cells and purified with a $95 \%$ of purity as stated in Fantinato et al. (2001). Recombinant DAAO variants R285A and mDAAO were produced in E. coli cells and purified both with a 95\% purity as stated in Molla et al. (2000) and Rosini et al. (2009). Recombinant D-aspartate oxidase (DASPO) and L-amino acid oxidase (LAAD) were produced in E. coli cells and purified with a 95 and $90 \%$ purity, respectively, as stated in Motta et al. (2016) and Molla et al. (2019). The specific activity of DAAO wild-type, R285A, and mDAAO are 120, 0.01, and $120 \mathrm{U} / \mathrm{mg}$, respectively. DASPO and LAAD show a specific activity of 95 and $3.8 \mathrm{U} / \mathrm{mg}$, respectively. Catalase was purchased from SigmaAldrich (Milan, Italy): specific activity $10,000 \mathrm{U} / \mathrm{mg}$ protein.

\section{Agar Diffusion Test}

Antibacterial activity of the different enzymes was evaluated against E. coli ATCC 35218, B. subtilis ATCC 6633, and S. aureus ATCC 6538P by agar diffusion assay (Finn, 1959). Fresh bacterial cultures, inoculated from overnight pre-cultures, were grown in LB or MHB2 medium until an $\mathrm{OD}_{600 \mathrm{~nm}}=0.4$ and then used to prepare agar plates containing Antibiotic Medium 1 (AM1) or Mueller-Hinton Agar (MHA) medium with or without adding increasing concentrations $(0.2,2,10 \mathrm{mM})$ of D-alanine (or D-aspartate for DASPO) or 0.2, 2, 10, 20 and 40 of D,L-alanine. A drop of $10 \mu \mathrm{l}$ containing increasing concentrations $(10,100,1,000 \mu \mathrm{g} / \mathrm{ml})$ of enzymes (wild-type, R285A variant, and mDAAO, DASPO or LAAD) were loaded onto the inoculated plates and then incubated at $37^{\circ} \mathrm{C}$ for $24 \mathrm{~h}$. The diameter of bacterial growth inhibition zone surrounding the site of drop deposition was measured.

The effect of catalase on the antibacterial activity of DAAO enzymes was tested on the same strains. Briefly, $10 \mu$ of catalase at $1 \mathrm{mg} / \mathrm{ml}$ concentration were added to inoculated AM1 or MHA plates with or without $10 \mathrm{mM}$ of $\mathrm{D}$-alanine together with $10 \mu \mathrm{l}$ of the enzymes at $1 \mathrm{mg} / \mathrm{ml}$ concentration.

\section{Determination of Minimal Inhibitory Concentration (MICs)}

Cultures of E. coli ATCC 35218, A. baumannii, P. aeruginosa ATCC 10145, S. enterica subsp. typhimurium ATCC 6994, E. faecalis, Y. enterocolitica, B. subtilis ATCC 6633, and S. aureus ATCC 6538P were treated as follows to determine the MICs of DAAO. Cryovials of glycerinates were thawed at room temperature 
and used to inoculate $\mathrm{LB}$ or MHB2 media. The strains were grown to exponential growth phase $\left(\sim \mathrm{OD}_{600 \mathrm{~nm}}=0.4\right)$ at $37^{\circ} \mathrm{C}$ with shaking at $200 \mathrm{rpm}$. Then, $10 \mu \mathrm{l}$ of cultures were seeded onto LB or $\mathrm{MH}$ agar plates supplemented with $10 \mathrm{mM} \mathrm{D}$-alanine and increasing concentrations of DAAO: from 0 to $100 \mu \mathrm{g} / \mathrm{ml}$ in $10 \mu \mathrm{g} / \mathrm{ml}$ increments. Following drying, plates were incubated at $37^{\circ} \mathrm{C}$. The MIC values represent the lowest DAAO concentration that inhibited visible growth after $24 \mathrm{~h}$ of incubation.

\section{Liquid Growth Kinetics}

Growth kinetics of liquid cultures of B. subtilis ATCC 6633, S. aureus ATCC 6538P, and E. coli ATCC 35218 were recorded by measuring the $\mathrm{OD}_{590 \mathrm{~nm}}$ using an Infinite ${ }^{\circledR} 200$ spectrophotometer (TECAN, Milan) at regular time intervals. Preinocula were prepared from cultures in LB or MHB2 medium grown overnight (at $37^{\circ} \mathrm{C}$ and at $200 \mathrm{rpm}$ ). Experiments were carried out in 96 well plates: each well, containing $200 \mu \mathrm{l}$ of LB or MHB2 medium, was added of $10 \mu \mathrm{g}$ of DAAO (corresponding to 1.2 units) and $10 \mathrm{mM}$ substrate.

\section{Bactericidal Effect of D-Amino Acid Oxidase on Grated Cheese}

A total of $10 \mathrm{~g}$ of a commercial grated cheese (mix of Grana Padano and Parmigiano Reggiano 12 months ripened, previously sterilized by UV irradiation to eliminate the innate onset of bacteria) were left in Petri dishes and incubated at room temperature for a maximum of $168 \mathrm{~h}$. Every $24 \mathrm{~h}$, the cheese sample from one plate was processed as reported in Rosini et al. (2008). Briefly, the fat part was removed by centrifugation and the water extract was plated on LB agar with or without adding $0.4 \%$ (w/v) DAAO (1 mg/ml, corresponding to 2.4 units per plate). After $16 \mathrm{~h}$ of incubation at $37^{\circ} \mathrm{C}$, microbial colonies were counted and expressed as colonies forming unit $(\mathrm{CFU}) / \mathrm{g}$ grated cheese.

\section{Bacteriological Analysis and Total D-Amino Acids Content of Food Samples}

Samples of parmesan, different baby food (fruit, turkey, and fish), and raw chicken breast meat fillets were provided by local supermarket. Cheese, baby food, and meat samples were divided into portions of $1 \mathrm{~g}$ each and left in sterile Petri dishes with $0.4 \%(\mathrm{w} / \mathrm{v})$ DAAO $(1 \mathrm{mg} / \mathrm{ml})$. The control samples were similarly prepared, except for adding DAAO. Each condition was tested in triplicate. Petri dishes were stored at $6 \pm 1{ }^{\circ} \mathrm{C}$ for 15 days and then analyzed for microbial counts.

Each sample was diluted $[10 \%(\mathrm{w} / \mathrm{v})]$ in buffered peptone water and mixed for 2 min using a vortex. The suspension of parmesan was treated as reported in Rosini et al. (2008), see above. The suspension of other food specimen was 10 -fold serially diluted in the buffered peptone water. An aliquot of $10 \mu \mathrm{l}$ of each sample was subsequently plated in triplicate on different media (Mc Conkey, Brilliant Green and MHA). Plates were examined visually for colony type and morphological characteristics based on the selective growth medium used. After incubation for $24-48 \mathrm{~h}$ at $37^{\circ} \mathrm{C}$, colonies were counted and expressed as $\log _{10}$ colonies forming unit (CFU)/g food sample.
Total D-amino acid content in food samples was assayed using a fluorescence-based biosensor made of two cuvettes for fluorescence analysis containing the Nile Red fluorescence dye and a mixture of $\mathrm{M} 213 \mathrm{G}$ and T60A/Q144R/K152E DAAO variants (0.5 $\mu \mathrm{M}$ each), respectively (Rosini et al., 2008, 2014). A calibration curve was obtained using a standard D-alanine solution (in the $0-25 \mu \mathrm{M}$ concentration range, $n=3$ ). The fluorescence emission values were recorded at $623 \mathrm{~nm}$ with excitation at $450 \mathrm{~nm}$, using a Jasco FP-750 spectrofluorimeter (Jasco, Cremello, Italy), at room temperature. The detection limit was $0.1 \mu \mathrm{M}$, with a limit of quantification of $0.22 \mu \mathrm{M}$. $\mathrm{D}$-amino acids solutions ( $5 \mu \mathrm{M}$ final concentration) containing different ratios of $\mathrm{D}$-alanine $(0-5.0 \mu \mathrm{M})$, D-glutamate $(0-4.0 \mu \mathrm{M})$, D-lysine $(0-4.0 \mu \mathrm{M})$, D-glutamine $(0-1.7 \mu \mathrm{M})$, and D-methionine $(0-1.0 \mu \mathrm{M})$ were used to evaluate the effect of the substrate composition on the biosensor response; a mean relative fluorescence value corresponding to $\approx 70 \%$ of the value obtained on $5 \mu \mathrm{M}$ D-alanine was measured. Homogenized samples and the chicken breast meat fillet were suspended in $100 \mathrm{mM}$ disodium pyrophosphate buffer, $\mathrm{pH} 8.5$ at a final concentration of $0.1 \mathrm{~g} / \mathrm{ml}$ and incubated for $15 \mathrm{~min}$ at $20^{\circ} \mathrm{C}$ in an ultrasonic bath. The suspension was centrifuged at $11,000 \mathrm{~g}$ for $30 \mathrm{~min}$ at $4^{\circ} \mathrm{C}$, and the supernatant was used for biosensor measurements.

\section{RESULTS}

\section{Antibacterial Activity of D-Amino Acid Oxidase: Plate Assay}

At first, the antibacterial activity of DAAO was investigated using an agar plate diffusion assay by comparing the growth inhibitory effects on two commonly used Gram-positive bacteria, i.e., S. aureus ATCC 6538P and B. subtilis ATCC 6633, and on the Gram-negative bacteria E. coli ATCC 35218. Assays were carried out with or without adding the DAAO substrate in the plates (i.e., $0.2,2$, and $10 \mathrm{mM} \mathrm{D}$-alanine or $0.2,2,10$, 20 , and $40 \mathrm{mM}$ of $\mathrm{D}, \mathrm{L}$-alanine). Wild-type DAAO inhibited the growth of all the strains tested only when D-alanine was present in the medium: L-alanine at the same concentrations did not allow the formation of inhibition halos, as expected since L-amino acids are not substrates of DAAO (data not shown) (Pollegioni et al., 2008). The halos were more clearly visible using $10 \mathrm{mM}$ of $\mathrm{D}$-alanine: accordingly, this concentration was used in the following tests. The best condition in terms of halo size $(10 \mathrm{~mm})$ was observed using $10 \mathrm{mM}$ of $\mathrm{D}$-alanine or $20 \mathrm{mM} \mathrm{D}$,L-alanine (indicating that the racemic amino acid mixture can be also used) and $0.01 \mathrm{mg}$ of DAAO corresponding to 1.2 units (per plate, Figure 1A). The same assay was also performed using an identical amount of R285A (an inactive variant, corresponding to 0.0001 units) or mDAAO (a variant also active at low $\mathrm{O}_{2}$ concentration based on a $\sim 10$-fold lower $\mathrm{K}_{\mathrm{m}}$ for dioxygen, corresponding to 1.2 units at air $\mathrm{O}_{2}$ saturation) DAAO variants: the $\mathrm{R} 285 \mathrm{~A}$ variant did not produce any inhibition halos, while the halos generated by mDAAO were comparable (11 mm vs. $10 \mathrm{~mm}$, respectively) to those produced by DAAO wild-type (Figure 1B). 


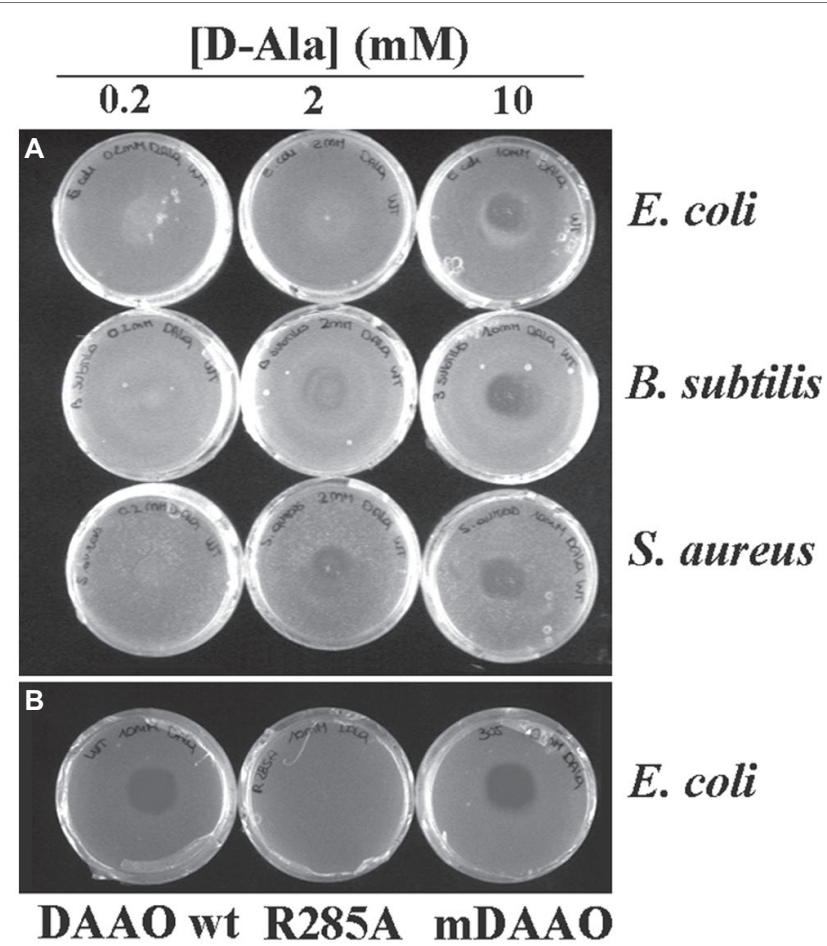

FIGURE 1 | Antibacterial activity of DAAO. (A) Plates of E. coli ATCC 35218 (top), B. subtilis ATCC 6633 (middle), and S. aureus ATCC 6538P (bottom) incubated with different concentrations of D-Ala $(0.2 \mathrm{mM}$ on the left, $2 \mathrm{mM}$ on the center, and $10 \mathrm{mM}$ on the right) using $0.01 \mathrm{mg}$ of DAAO corresponding to 1.2 units per plate. (B) Plates of E. coli ATCC 35218 incubated with $10 \mathrm{mM}$ D-Ala and $0.01 \mathrm{mg}$ of different variants of DAAO: wild-type (left), R285A (middle) and mDAAO (right).

We then examined the minimal bactericidal activity of DAAO against E. coli ATCC 35218, A. baumannii, $P$ aeruginosa ATCC10145, S. enterica subsp. typhimurium ATCC 6994, E. faecalis, Y. enterocolitica, B. subtilis ATCC 6633, and S. aureus ATCC 6538P. All bacteria were incubated with DAAO at various concentrations in the presence of $10 \mathrm{mM} \mathrm{D}$-alanine in $\mathrm{LB}$ or $\mathrm{MH}$ agar medium. A total of 10,20 , and $25 \mu \mathrm{g} / \mathrm{ml}$ of DAAO yielded E. faecalis, $Y$. enterocolitica, and $S$. aureus growth inhibition, respectively. The minimal concentration of DAAO required to inhibit $E$. coli and B. subtilis growth was $50 \mu \mathrm{g} /$ $\mathrm{ml}$, while to inhibit $A$. baumannii and $P$. aeruginosa growth was 60 and $70 \mu \mathrm{g} / \mathrm{ml}$, respectively. Notably, S. enterica subsp. typhimurium growth was not affected by the DAAO-Dalanine treatment.

\section{Identification of the Antibacterial Agent}

To prove that the antibacterial effect is due to the production of hydrogen peroxide by DAAO, the assay was carried out on plates loading $0.01 \mathrm{mg}$ of wild-type DAAO (approx. 1.2 unit) with or without adding the same amount of catalase, an enzyme that eliminates the hydrogen peroxide produced by DAAO (because of the high specific activity of catalase, the used amount corresponds to a 5,000-fold excess compared to DAAO in terms of enzymatic units). In the presence of catalase, no bactericidal

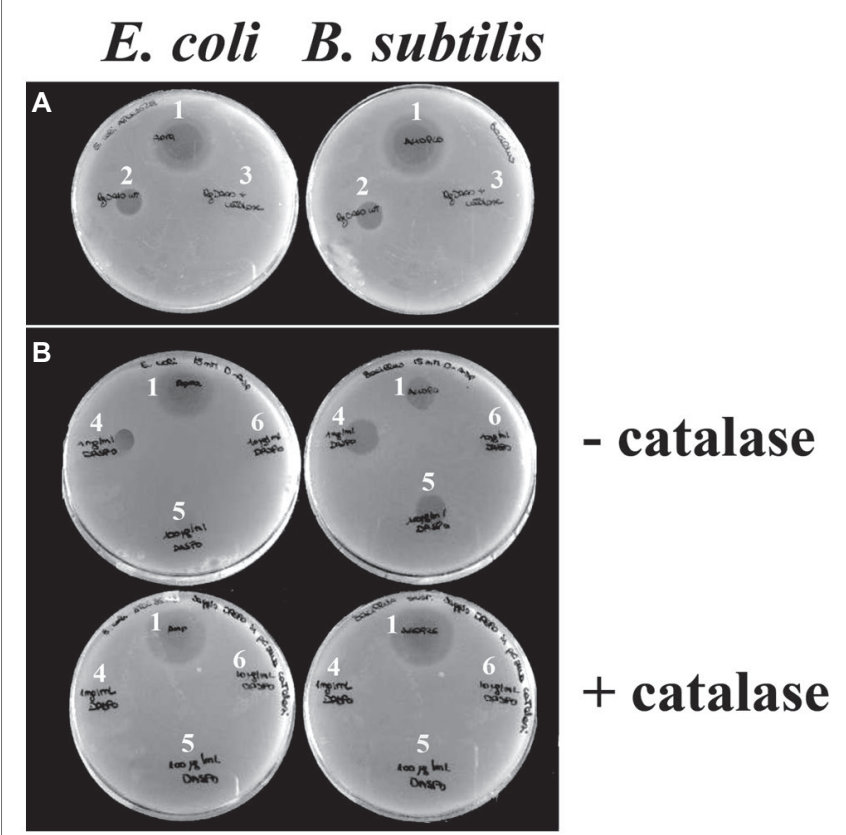

FIGURE 2 | Effect of catalase on DAAO and DASPO antibacterial activity. Plates containing E. coli ATCC 35218 (left) and plates containing B. subtilis ATCC 6633 (right). (A) For both plates, it is possible to appreciate an halo due to an antibiotic (as positive control, 1) and an halo due to DAAO (2); no inhibition halo was apparent where the mixture DAAO-catalase was loaded (3). (B) In top panels, where no catalase is present, it is possible to appreciate inhibition halos with different sizes depending on the quantity of DASPO enzyme loaded $10 \mu \mathrm{l}$ of [(4) $1,000 \mu \mathrm{g} / \mathrm{ml}$; (5) $100 \mu \mathrm{g} / \mathrm{ml}$; (6) $10 \mu \mathrm{g} / \mathrm{ml}$. In both cases, the wider halo is the one where $10 \mu \mathrm{g}$ of enzyme were plated (4). In the presence of catalase (bottom panels), halo is observed only where the antibiotic was loaded (1).

effect is observed, thus strongly supporting hydrogen peroxide as the antibacterial agent (Figure $\mathbf{2 A}$ ).

To confirm the proposal that the antibacterial activity of DAAO is mainly due to hydrogen peroxide generation during the reaction with $\mathrm{D}$-alanine present in the medium, we used an alternative flavoenzyme also able to efficiently generate hydrogen peroxide such as D-aspartate oxidase (DASPO). To this purpose, E. coli and B. subtilis were incorporated into agar plates containing $15 \mathrm{mM}$ of D-aspartate (the best substrate of DASPO) (Katane et al., 2007) and added of $10 \mu \mathrm{l}$ of DASPO at different concentrations $(10,100$, and $1,000 \mu \mathrm{g} / \mathrm{ml}$ corresponding to $\sim 0.0095,0.095$, and 0.95 units, respectively) with or without adding the catalase, see above. As shown in Figure $\mathbf{2 B}$, in the absence of catalase the wider inhibition halo $(13 \mathrm{~mm})$ is formed in the presence of the highest amount of DASPO (10 $\mu \mathrm{g}$ per plate). No halos are visible in the presence of catalase.

To further endorse the fact that the antibacterial activity of DAAO is due to the production of hydrogen peroxide, a diffusion agar test was done using a plate containing $10 \mathrm{mM}$ of L-phenylalanine and loading different quantities of L-amino acid deaminase (LAAD). This flavoenzyme, a member of amino acid oxidase family, deaminates L-amino acids with no hydrogen peroxide production (Motta et al., 2016). 
In this case, no halos are observed in all the conditions tested (data not shown).

\section{Antibacterial Activity of D-Amino Acid Oxidase: Liquid Culture}

We further investigated the effect of wild-type DAAO and its R285A and mDAAO variants, on bacterial viability by adding the enzymes at the log phase of growth of E. coli ATCC 35218 (Figure 3A), B. subtilis ATCC 6633 (Figure 3B), and S. aureus ATCC 6538P (Figure 3C) cultivations. Cultures with no added enzymes or to which antibiotics or hydrogen peroxide were added have been used as negative and positive controls, respectively. Figure 3 shows that the three strains equally responded to the enzymes' addition. As expected, the growth kinetics were dramatically affected by hydrogen peroxide or ampicillin (for E. coli) or teicoplanin (for Gram-positive bacteria): albeit with a slightly different kinetics, cell density was drastically reduced after $5 \mathrm{~h}$ of incubation. Indeed, the active wild-type and mDAAO variant (differing in $\mathrm{O}_{2}$ affinity) similarly reduced by half the growth of the three strains. This result indicates that DAAO antibacterial activity is not affected by $\mathrm{O}_{2}$ concentration under the tested conditions. Finally, the R285A DAAO variant (inactive) did not affect growth of the tested strains.

\section{Antibacterial Effect of D-Amino Acid Oxidase on Foods}

To check whether DAAO is able to reduce bacterial contamination on food samples, seven samples containing $10 \mathrm{~g}$ of grated cheese each (i.e., a commercial mixture of different cheeses) were analyzed following the protocol of Rosini et al. (2008) to remove the fat component of cheese: $100 \mu \mathrm{l}$ of supernatant were plated with or without adding $0.01 \mathrm{mg}$ of wild-type DAAO (corresponding to 1.2 units). After $16 \mathrm{~h}$ of incubation at $37^{\circ} \mathrm{C}, \mathrm{CFU}$ were counted. As shown in Figure 4A, when no enzyme was added to the supernatant approximately 10 times more colonies were counted than in plates spread with supernatant plus DAAO. This result demonstrates once more the antimicrobial activity of DAAO enzyme.

Subsequently, the same experiment was performed on slices of parmesan. For this purpose, a slice of parmesan (1 g) was spread with $0.4 \%$ (w/w) DAAO (2.4 units); a slice of untreated parmesan was used as control. The cheese's slices were conserved into Petri dishes in the fridge $\left(6^{\circ} \mathrm{C}\right)$ for 15 days. At the end of the incubation period, the parmesan was processed as reported in section "Materials and methods" (section "Bactericidal Effect of D-Amino Acid Oxidase on Grated Cheese") and the supernatants plated on two different selective media (AM1 or MHA to promote Gram-positive or Gram-negative bacteria growth, respectively). As shown in Figure $4 \mathrm{~B}$, in both media a higher concentration of bacteria was detectable in the slices not containing DAAO than in DAAO containing samples. This result allows to propose the use of DAAO as preservative agent for cheeses.

In order to verify the effectiveness of DAAO as biopreservative agent, four additional food samples (i.e.,

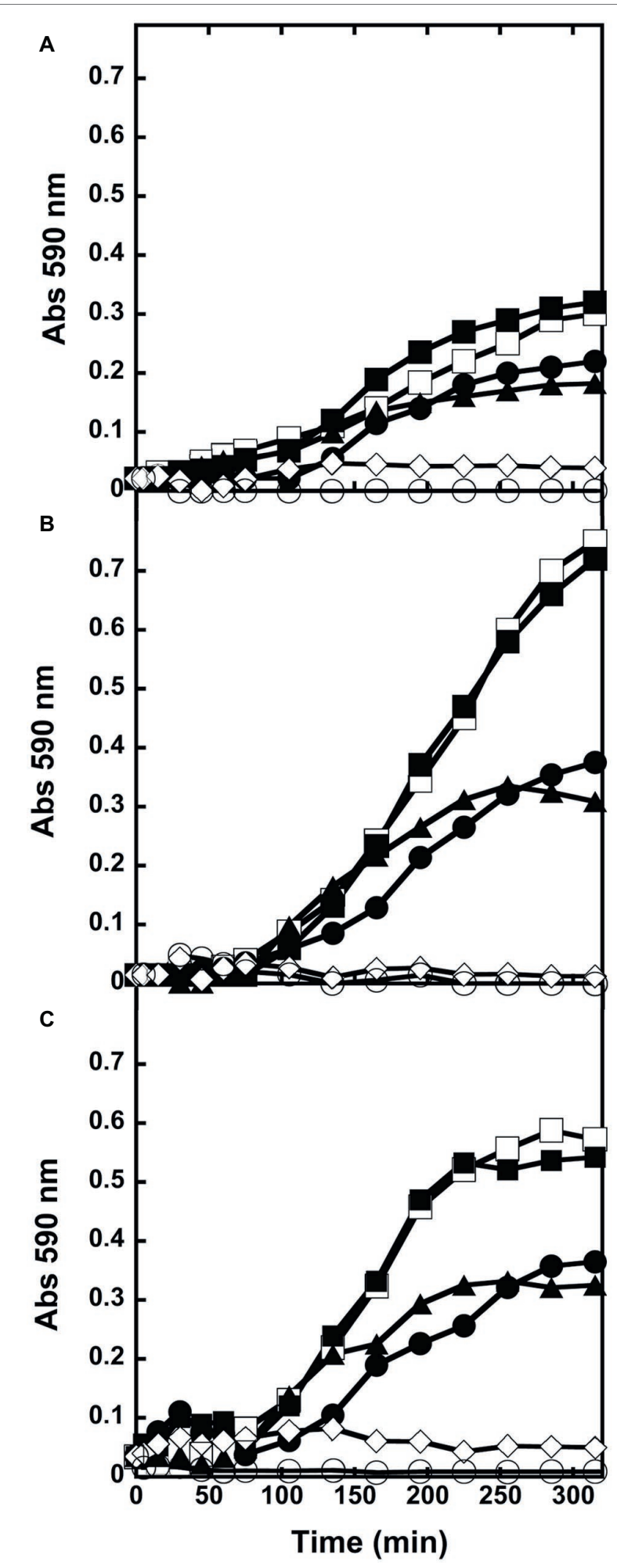

FIGURE 3 | Kinetics of growth of liquid cultures. (A) E. coli ATCC 35218, (B) B. subtilis ATCC 6633, and (C) S. aureus ATCC 6538P exposed to wild-type $(\bullet)$, R285A ( $\square$ ), mDAAO $(\mathbf{A})$, antibiotic $(\diamond)$ or hydrogen peroxide (O). Cultures without any addition ( $\square$ ) were used as controls. Growth was recorded for $5 \mathrm{~h}$. Triplicate experiments were conducted for each condition: standard errors were lower than $5 \%$. 
homogenates of fruit, fish, turkey, and chicken breast meat fillets) were conserved at $6^{\circ} \mathrm{C}$ in sterile Petri's dishes with or without adding DAAO $[0.4 \%(\mathrm{w} / \mathrm{w})$ corresponding to $2 \mathrm{U} / \mathrm{g}$ of food]. After 2 weeks, all the samples were diluted [10\% $(w / v)]$ in buffered peptone water as enrichment media, and then $0.01 \mathrm{ml}$ of 10 -fold diluted suspension was plated in triplicate on different selective media (Mc Conkey, Brilliant Green and MHA). After $24-48 \mathrm{~h}$ at $37^{\circ} \mathrm{C}$, plates were observed for morphology and counted for the total number of CFU (see Figure 5 where data are expressed as $\log _{10} \mathrm{CFU} / \mathrm{g}$ food sample). As a general rule, the plates containing DAAOtreated samples show a lower development of colonies respect to plates with samples incubated without DAAO. In the plates containing agar Mc Conkey medium, selective for Gram-negative bacteria, several pink to red colonies were observed indicative of lactose-fermenting organisms, such as E. coli and Klebsiella spp.: only few colorless or clear colonies were apparent, indicating lactose-non-fermenting organisms, such as Salmonella, Shigella, and Proteus spp. No red-pink-white opaque colored colonies surrounded by brilliant red zones were found in plates containing Brilliant Green agar medium (indicating the bacteria belonging to Salmonella genus), neither small red colonies (indicating absence of Proteus and Pseudomonas species).

In these treatments, the DAAO antibacterial activity is based on the use of D-amino acids present in the foodstuffs: actually, no effect was observed for the chicken sample, which does not contain D-amino acids (Table 1). The total D-amino acids concentration in the food samples does not correspond to the observed inhibition of bacterial growth: the highest antibacterial effect was observed for the fish sample, while the highest D-amino acid level was apparent in the fruit one (Table 1). This observation indicates that the $\mathrm{D}$-amino acid composition and the original bacterial composition in the different food samples affect the DAAO antibacterial activity. Such an effect is probably related to the ripening food process: over the time, some bacteria can release D-amino acids in the media (Genchi, 2017).
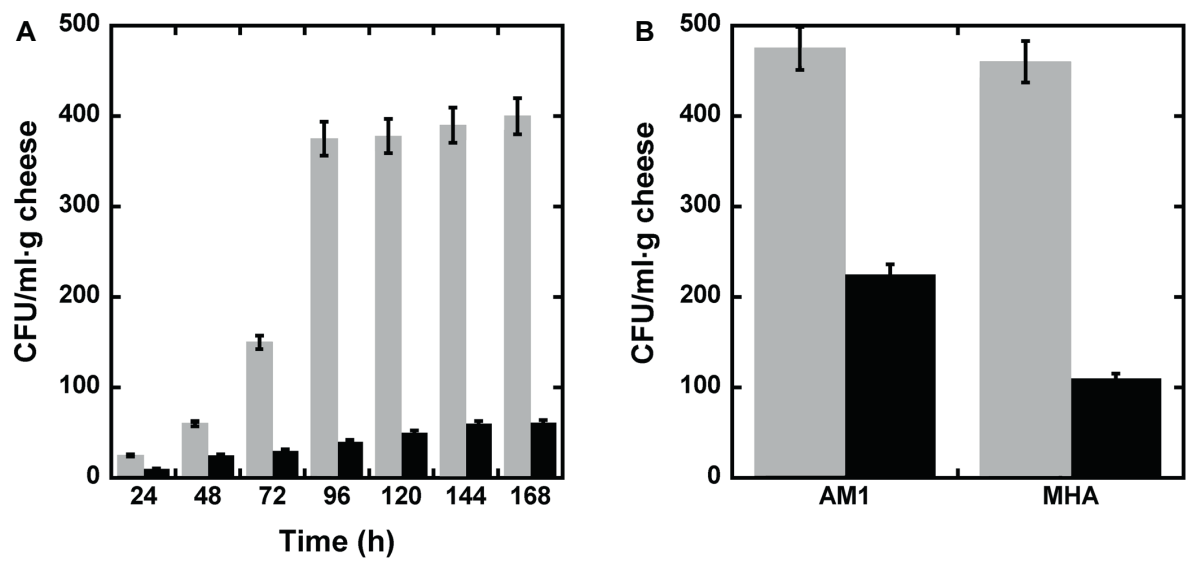

FIGURE 4 | Bactericidal activity of DAAO. (A) Bacterial cell viability measured, every $24 \mathrm{~h}$ of incubation, as CFU/ml.g of grated cheese in the presence (black bars) or absence (untreated control, light gray bars) of DAAO. (B) Bacterial cell viability measured after 15 days of incubation, as CFU/ml.g of parmesan in the presence (black bar) or absence (untreated control, light gray bars) of DAAO.

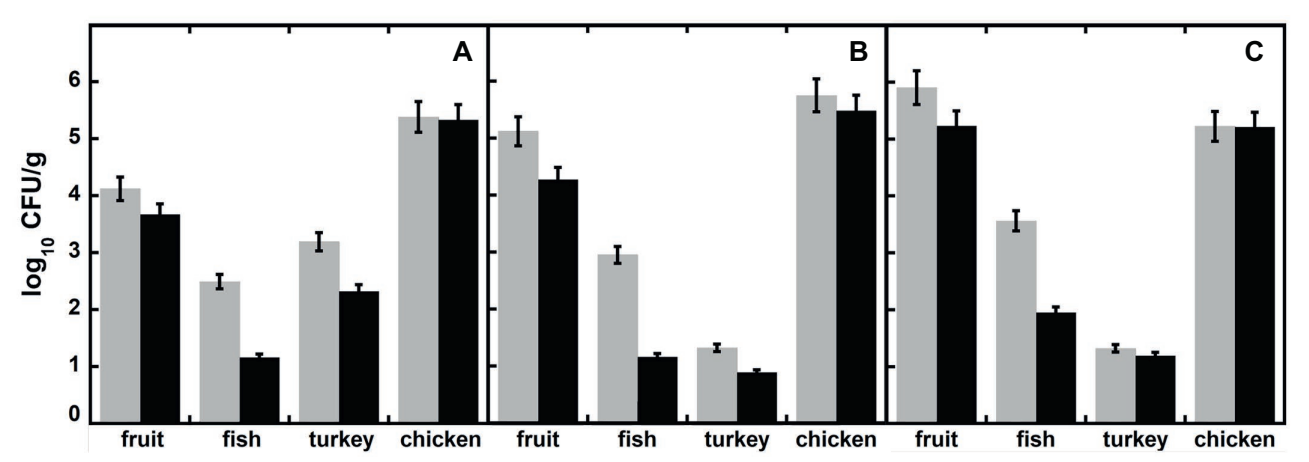

FIGURE 5 | Total viable bacteria (expressed as $\log _{10}$ CFU/g of food), in different food samples measured after 15 days of incubation, in the presence (black bars) or absence (untreated control, light gray bars) of DAAO. Samples were plated in different media: (A) Mc Conkey agar, (B) Brilliant Green, and (C) Mueller Hinton agar. 
TABLE 1 | Amount of total D-amino acids in different foods and average bacterial growth inhibition induced by DAAO treatment $(2 \mathrm{U} / \mathrm{g}$ food).

\begin{tabular}{lccc}
\hline & \multicolumn{2}{c}{$\mathbf{D}-$ Amino acids } & $\begin{array}{c}\text { Bacterial } \\
\text { inhibition }\end{array}$ \\
\cline { 2 - 4 } & $\mathbf{( m M )}$ & $\mathbf{( m g / g}$ food) & $\mathbf{( \% )}$ \\
\hline Cheese & $10.5 \pm 1.5$ & $7.2 \pm 1.0$ & 85 \\
Fruit & $1.4 \pm 0.2$ & $1.6 \pm 0.2$ & 58 \\
Fish & $0.2 \pm 0.01$ & $0.2 \pm 0.01$ & 97 \\
Turkey & $0.9 \pm 0.1$ & $1.1 \pm 0.1$ & 65 \\
Chicken & b.d. & b.d. & 16 \\
\hline
\end{tabular}

b.d., below detection.

\section{DISCUSSION}

The antimicrobial activity of DAAO was first reported by Cline and Lehrer in 1969 related to its putative physiological role in leukocytes (Cline and Lehrer, 1969), followed by a couple of additional studies (Zhang et al., 2004; Nakamura et al., 2012). To the best of our knowledge, this is the first report on using DAAO as an antibacterial agent applied at foodstuffs. We selected DAAO from the yeast Rhodotorula gracilis for this application since it can be overexpressed in huge amounts in E. coli cells (up to $100 \mathrm{mg} / \mathrm{l}$ fermentation broth and at low cost, $0.04 € /$ enzyme unit) (Romano et al., 2009); it shows a strong interaction with the FAD cofactor (i.e., it is always present in solution as active holoenzyme) (Pollegioni et al., 2007), a high kinetic efficiency (maximal activity at air $\mathrm{O}_{2}$-saturation is $>100 \mathrm{U} / \mathrm{mg}$ protein), a broad substrate preference for $\mathrm{D}$-amino acids (only acidic $\mathrm{D}$-amino acids are not oxidized), and absence of inhibition by the L-enantiomer. Because of the latter property, racemic mixtures of amino acids can be used instead of pure D-amino acid solutions, resulting in a lower cost of the assay.

In the present work, we tested the antibacterial activity of DAAO by diffusion agar test and liquid growth kinetics: in both cases, we demonstrated that active wild-type DAAO and its variant $\mathrm{mDAAO}$ are able to inhibit bacterial growth producing an inhibition halo on cultures grown on agar medium and to reduce by half the growth in liquid culture. Furthermore, the antibacterial activity was proved against both Gram-positive (B. subtilis and S. aureus) and Gram-negative (E. coli) bacteria. In order to verify that the DAAO antibacterial activity is due to hydrogen peroxide production, we compared the DAAO effect with that of two related amino acid oxidases: DASPO, a hydrogen peroxide producing flavoenzyme, behaved similarly to DAAO, while LAAD, which is known to transfer electrons from reduced $\mathrm{FAD}$ to a cytochrome b-like protein with no $\mathrm{H}_{2} \mathrm{O}_{2}$ production (Motta et al., 2016), did not show any antibacterial activity. Indeed, both DAAO and DASPO in the presence of catalase, which catalyzes the decomposition of hydrogen peroxide to water and oxygen, lost the antibacterial activity. We conclude that the antibacterial activity of yeast $\mathrm{DAAO}$ is due to the production of hydrogen peroxide, thus confirming the conclusions from a previous study based on porcine DAAO (Nakamura et al., 2012). Our finding also agrees with in vivo results. Actually, the endogenous expression of DAAO in kidney was considered sufficient to reduce bacterial growth (Nakamura et al., 2012), and DAAO was reported to bind to bacterial cell walls, yielding a more localized and concentrated production of $\mathrm{H}_{2} \mathrm{O}_{2}$ (Zhang et al., 2004). DAAO showed antibacterial activity on seven out of the eight bacterial strains used: S. enterica subsp. typhimurium was not affected by the DAAO-D-alanine antibacterial treatment. This is an intriguing issue since Salmonella is known to evade the oxidative damage elicited by DAAO reaction in neutrophils by expressing an ABC importer specific for D-alanine (Tuinema et al., 2014).

In this work, DAAO has been evaluated for possible use in food preservation. In food samples, the development of bacteria on the plates was significantly reduced by treatment with DAAO in comparison to the untreated controls. Bacterial growth in grated cheese is reduced 10 -fold by adding DAAO, as well as the bacterial level in 2-weeks aged foodstuffs. Notably, in D-amino acid-rich foodstuffs, no exogenous addition of $\mathrm{D}$-amino acids is required to appreciate the antibacterial activity of DAAO.

The overall reaction catalyzed by DAAO involves the consumption of one D-amino acid and one oxygen molecule to produce one $\alpha$-keto acid, one ammonia, and one hydrogen peroxide molecule. This reaction uses $\mathrm{O}_{2}$, a property that could allow DAAO to be used as an active $\mathrm{O}_{2}$-scavenger, antioxidant, and preservative in food applications. For example, lipid oxidation can result in deterioration and rancid taste in high-fat foods, i.e., mayonnaise (Isaksen and Adler-Nissen, 1997). In canned/ bottled/packaged food, oxygen favors bacterial growth: $\mathrm{O}_{2}$ removal from the headspace helps to maintain an anaerobic environment (Kirk et al., 2002) and to preserve taste and flavor of beverages such as wine and beer (Labuza and Breene, 1989; Dube et al., 2017). Glucose oxidase is typically used as food processing-additive in a mixture with catalase, since the two enzymes are present together in the mycelium cell wall of fungi and enzyme isolation is costly: while this system works well in $\mathrm{O}_{2}$ scavenging, the antibacterial activity is limited by deactivation of hydrogen peroxide (Wong et al., 2008). On the contrary, based on the low amount required and the low cost of production, DAAO is used as purified preparation: this allows both efficient hydrogen peroxide generation and $\mathrm{O}_{2}$-consumption. Moreover, DAAO is supposed to be safe for human consumption, since it is normally expressed in human tissues among which the small intestine (Pollegioni et al., 2007; Sasabe et al., 2016; Sacchi et al., 2018). In addition, it has also been already demonstrated that DAAO alone shows no cytotoxicity against human cells (Rosini et al., 2009).

In conclusion, these results combined with the request from consumers to replace chemical antioxidants and oxygen scavengers with natural compounds, making DAAO an ideal candidate in food preservation.

\section{STATISTICS}

All experiments were replicated three times. Mean and standard deviation (SD) were calculated using Microsoft 
Excel 2003 (Microsoft Co., Redmond, WA, United States). One-way analysis of variance was performed using Origin_7.0 SR0 (Origin lab Co., Northampton, MA, USA). Significant effects of treatments were estimated $(p<0.05, p<0.01$, and $p<0.0001)$.

\section{DATA AVAILABILITY STATEMENT}

All datasets generated for this study are included in the article.

\section{AUTHOR CONTRIBUTIONS}

GM and LP conceived the experiments and interpreted the results. $\mathrm{EB}, \mathrm{MA}$, and $\mathrm{GM}$ carried out and interpreted the

\section{REFERENCES}

Brul, S., and Coote, P. (1999). Preservative agents in foods. Mode of action and microbial resistance mechanisms. Int. J. Food Microbiol. 50, 1-17. doi: 10.1016/S0168-1605(99)00072-0

Cline, M. J., and Lehrer, R. I. (1969). D-amino acid oxidase in leukocytes: a possible D-amino acid linked antimicrobial system. Proc. Natl. Acad. Sci. USA 62, 756-763. doi: 10.1073/pnas.62.3.756

Dube, M. K., Zehra, A., Aamir, M., Meena, M., Ahirwal, L., Singh, S., et al. (2017). Improvement strategies, cost effective production, and potential applications of fungal glucose oxidase (GOD): current updates. Front. Microbiol. 8:1032. doi: $10.3389 /$ fmicb.2017.01032

Fantinato, S., Pollegioni, L., and Pilone, M. S. (2001). Engineering, expression and purification of a His-tagged chimeric D-amino acid oxidase from Rhodotorula gracilis. Enzym. Microb. Technol. 29, 407-412. doi: 10.1016/ S0141-0229(01)00400-8

Finn, R. K. (1959). Theory of agar diffusion methods for bioassay. Anal. Chem. 31, 975-977. doi: 10.1021/ac60150a040

Genchi, G. (2017). An overview on D-amino acids. Amino Acids 49, 1521-1533. doi: 10.1007/s00726-017-2459-5

Isaksen, A., and Adler-Nissen, J. (1997). Antioxidative effect of glucose oxidase and catalase in mayonnaises of different oxidative susceptibility. I. Product trials. Lebensm. Wiss. Technol. 30, 841-846. doi: 10.1006/fstl.1997.0283

Juven, B. J., and Pierson, M. D. (1996). Antibacterial effects of hydrogen peroxide and methods for its detection and quantitation. J. Food Prot. 59, 1233-1241. doi: 10.4315/0362-028X-59.11.1233

Katane, M., Furuchi, T., Sekine, M., and Homma, H. (2007). Molecular cloning of a cDNA encoding mouse $\mathrm{D}$-aspartate oxidase and functional characterization of its recombinant proteins by site-directed mutagenesis. Amino Acids 32, 69-78. doi: 10.1007/s00726-006-0350-x

Kirk, O., Borchert, T. V., and Fuglsang, C. C. (2002). Industrial enzyme applications. Curr. Opin. Biotechnol. 13, 345-351. doi: 10.1016/S0958-1669(02)00328-2

Labuza, T. P., and Breene, W. M. (1989). Applications of "active packaging" for improvement of shelf-life and nutritional quality of fresh and extended shelf-life foods 1. J. Food Process. Preserv. 13, 1-69. doi: 10.1111/ j.1745-4549.1989.tb00090.x

Molla, G., Chaves-Sanjuan, A., Savinelli, A., Nardini, M., and Pollegioni, L. (2019). Structure and kinetic properties of human D-aspartate oxidase, the enzyme controlling D-aspartate levels in brain. FASEB J. (in press).

Molla, G., Porrini, D., Job, V., Motteran, L., Vegezzi, C., Campaner, S., et al. (2000). Role of arginine 285 in the active site of Rhodotorula gracilis D-amino acid oxidase. A site-directed mutagenesis study. J. Biol. Chem. 275, 24715-24721. doi: 10.1074/jbc.M908193199

Motta, P., Molla, G., Pollegioni, L., and Nardini, M. (2016). Structure-function relationships in L-amino acid deaminase, a flavoprotein belonging to a novel class of biotechnologically relevant enzymes. J. Biol. Chem. 291, 10457-10475. doi: 10.1074/jbc.M115.703819 microbiology experiments. ER determined D-amino acid content in foods. GM and LP wrote the manuscript. All authors reviewed and approved the final manuscript.

\section{FUNDING}

This work was supported by grant "Fondo di Ateneo per la Ricerca" 2017 to GM and LP and "Fondo di Ateneo per la Ricerca" 2018 to GM, ER, and LP.

\section{ACKNOWLEDGMENTS}

We acknowledge the support of Consorzio Interuniversitario per le Biotecnologie to GM, EB, and LP.

Nakamura, H., Fang, J., and Maeda, H. (2012). Protective role of D-amino acid oxidase against Staphylococcus aureus infection. Infect. Immun. 80, 1546-1553. doi: 10.1128/IAI.06214-11

Pilone, M. S., and Pollegioni, L. (2002). D-amino acid oxidase as an industrial biocatalyst. Biocatal. Biotransformation 20, 145-159. doi: 10.1080/ 10242420290020679

Pilone, M. S., Pollegioni, L., Casalin, P., Curti, B., and Ronchi, S. (1989). Properties of D-amino-acid oxidase from Rhodotorula gracilis. Eur. J. Biochem. 180, 199-204.

Pollegioni, L., Langkau, B., Tischer, W., Ghisla, S., and Pilone, M. S. (1993). Kinetic mechanism of D-amino acid oxidases from Rhodotorula gracilis and Trigonopsis variabilis. J. Biol. Chem. 268, 13850-13857.

Pollegioni, L., and Molla, G. (2011). New biotech applications from evolved D-amino acid oxidases. Trends Biotechnol. 29, 276-283. doi: 10.1016/j. tibtech.2011.01.010

Pollegioni, L., Molla, G., Sacchi, S., Rosini, E., Verga, R., and Pilone, M. S. (2008). Properties and applications of microbial D-amino acid oxidases: current state and perspectives. Appl. Microbiol. Biotechnol. 78, 1-16. doi: 10.1007/s00253-007-1282-4

Pollegioni, L., Piubelli, L., Sacchi, S., Pilone, M. S., and Molla, G. (2007). Physiological functions of $\mathrm{D}$-amino acid oxidases: from yeast to humans. Cell. Mol. Life Sci. 64, 1373-1394. doi: 10.1007/s00018-007-6558-4

Romano, D., Molla, G., Pollegioni, L., and Marinelli, F. (2009). Optimization of human D-amino acid oxidase expression in Escherichia coli. Protein Expr. Purif. 68, 72-78. doi: 10.1016/j.pep.2009.05.013

Rosini, E., Molla, G., Rossetti, C., Pilone, M. S., Pollegioni, L., and Sacchi, S. (2008). A biosensor for all D-amino acids using evolved D-amino acid oxidase. J. Biotechnol. 135, 377-384. doi: 10.1016/j.jbiotec.2008.06.001

Rosini, E., Piubelli, L., Molla, G., Frattini, L., Valentino, M., Varriale, A., et al. (2014). Novel biosensors based on optimized glycine oxidase. FEBS J. 281, 3460-3472. doi: 10.1111/febs. 12873

Rosini, E., Pollegioni, L., Ghisla, S., Orru, R., and Molla, G. (2009). Optimization of D-amino acid oxidase for low substrate concentrations towards a cancer enzyme therapy. FEBS J. 276, 4921-4932. doi: 10.1111/j.1742-4658.2009.07191.x

Sacchi, S., Cappelletti, P., and Murtas, G. (2018). Biochemical properties of human D-amino acid oxidase variants and their potential significance in pathologies. Front. Mol. Biosci. 5:55. doi: 10.3389/fmolb.2018.00055

Sasabe, J., Miyoshi, Y., Rakoff-Nahoum, S., Zhang, T., Mita, M., Davis, B. M., et al. (2016). Interplay between microbial D-amino acids and host D-amino acid oxidase modifies murine mucosal defence and gut microbiota. Nat Microbiol. 1, 16125-16141. doi: 10.1038/nmicrobiol.2016.125

Tajkarimi, M. M., Ibrahim, S. A., and Cliver, D. O. (2010). Antimicrobial herb and spice compounds in food. Food Control 21, 1199-1218. doi: 10.1016/j. foodcont.2010.02.003

Tuinema, B. R., Reid-Tu, S. A., and Coombes, B. K. (2014). Salmonella evades D-amino acid oxidase to promote infection in neutrophils. MBio 5, e01886-e01814. doi: 10.1128/mBio.01886-14 
Vijayakumar, R., and Sandle, T. (2019). A review on biocide reduced susceptibility due to plasmid-borne antiseptic-resistant genes-special notes on pharmaceutical environmental isolates. J. Appl. Microbiol. 126, 1011-1022. doi: 10.1111/ jam. 14118

Wong, C. M., Wong, K. H., and Chen, X. D. (2008). Glucose oxidase: natural occurrence, function, properties and industrial applications. Appl. Microbiol. Biotechnol. 78, 927-938. doi: 10.1007/s00253-008-1407-4

Zhang, H., Yang, Q., Sun, M., Teng, M., and Niu, L. (2004). Hydrogen peroxide produced by two amino acid oxidases mediates antibacterial actions. J. Microbiol. 42, 336-339.
Conflict of Interest: The authors declare that the research was conducted in the absence of any commercial or financial relationships that could be construed as a potential conflict of interest.

Copyright (c) 2019 Marcone, Binda, Rosini, Abbondi and Pollegioni. This is an openaccess article distributed under the terms of the Creative Commons Attribution License (CC BY). The use, distribution or reproduction in other forums is permitted, provided the original author(s) and the copyright owner(s) are credited and that the original publication in this journal is cited, in accordance with accepted academic practice. No use, distribution or reproduction is permitted which does not comply with these terms. 